\title{
Emergency airway and ventilator procedures for community based home care staff validation of an educational program
}

\author{
Ann Marie Ramsey RN, MSN, CPNP ${ }^{1}$ (iD $\quad$ Sarah Brennan RN, BSN ${ }^{2}$ | \\ Adam Stricker RN, BSN ${ }^{1}$ ～Kurt Riek RTT, BS ${ }^{1}$ | Dana Brown RRT ${ }^{1}$ \\ Rachel Gurtowsky RN, MS, CPNP ${ }^{1}$ | Julie Sturza $M^{2} H^{3}$ । \\ Amy Goldstein Filbrun MD, $\mathrm{MPH}^{1}$
}

\footnotetext{
1 Pediatric Home Ventilator Program, Division of Pediatric Pulmonology, Michigan Medicine, University of Michigan, Ann Arbor, Michigan

2 Department of Nursing, Michigan Medicine, University of Michigan, Ann Arbor, Michigan

${ }^{3}$ Department of Pediatrics, Michigan Medicine, University of Michigan, Ann Arbor, Michigan

\section{Correspondence}

Ann Marie Ramsey, Pediatric Pulmonology, L2221 Women's Hospital, Michigan Medicine, 1500 East Medical Center, Ann Arbor, MI 48109-5212.

Email: amramsey@med.umich.edu
}

\begin{abstract}
Background: Children discharged home with tracheostomy and chronic mechanical ventilator support are at high risk for complications and adverse events. Private duty nursing and home respiratory care services are a critical support necessary for successful discharge. The literature suggests that there are opportunities for home care staff (HCS) to improve upon the skills necessary to assess and intervene in an emergency thereby increasing the likelihood of improving long-term outcomes.

Methods: HCS (RN, LPN, RRT) participated in a 4-h session comprised of lecture and simulation. Lecture content focused on tracheostomy safety, operation of the Trilogy and LTV home ventilators, and review of their common alarms. Simulation included two scenarios simulating tracheostomy decannulation and mucous plugging events. Participant comfort with tracheostomy and ventilator management skills were measured on a five item self-assessment tool and clinical knowledge was measured using an 11 item multiple choice skills test, both of which were completed before and after the session. We tested to see if there was a change in test scores from pre- to post-intervention.

Results: Fifty-four HCS participated in the program and provided complete data sets. The vast majority (68\%) were registered nurses, followed by licensed practical nurses (19\%) and respiratory therapists (12\%). Participant self-reported comfort with emergency skills prior to intervention was $3.2 / 5$ which increased to $4.1 / 5$ after intervention $(P>0.0001)$. Average test score prior to intervention was $62 \%$, post intervention score increased to $82 \%$ which represented significant improvement $(P>0.0001)$.

Discussion: $\mathrm{HCS}$ are generally unprepared to intervene in an acute airway or ventilator emergency. This short, manageable program provided education that resulted in a significant improvement in both skill level and confidence.
\end{abstract}

\section{KEYWORDS}

home care staff, mechanical ventilation, private duty nursing, simulation, tracheostomy decannulation 


\section{1 | INTRODUCTION}

Children discharged home with chronic respiratory failure requiring tracheostomy and ventilator support have complex care needs and have high rates of mortality ${ }^{1-4}$ and frequent hospital readmissions. ${ }^{5,6}$ While a portion of these deaths may be attributed to underlying disease, many are unexpected. ${ }^{2,3}$ Despite improvements in monitoring technology, mortality rates have remained high. ${ }^{4,6} \mathrm{~A}$ significant portion of these unexpected deaths can be attributed to preventable complications from the tracheostomy such as mucous plugging and accidental decannulation. ${ }^{3,4,6}$ These children have an increased risk for hypoxemic arrest which progresses to bradycardia and hypotension, and evolves into cardiac arrest. In most cases this complication is preventable if $\mathrm{HCS}$ can correctly identify the cause of the respiratory distress and implement correct and timely interventions. ${ }^{7-9}$

Recently, the American Thoracic Society published guidelines for community management of children requiring chronic invasive mechanical ventilation. ${ }^{10}$ These guidelines recommend private duty nurses to provide skilled assessment and care to these fragile children. Additional recommendations include "ongoing education to acquire, reinforce, and augment skills required for patient care be provided to both the family and professional caregivers of children requiring chronic home mechanical ventilation." ${ }^{10}$ However, there are no universal or state based standards of care for training HCS providing care for tracheostomy and ventilator dependent children. Home care agencies are responsible for training their staff and methods and standards vary significantly from agency to agency.

A variety of evidence suggests that training for home health care providers is inadequate. ${ }^{10-13}$ Families report that nurses are unskilled and surveys of home care nursing staff have identified knowledge deficiencies in many critical areas of care. ${ }^{3,9}$ In one study, $97 \%$ of homecare nurses surveyed reported an interest in receiving additional training in the management of tracheostomy and mechanical ventilation in the home. ${ }^{7}$ A simulation study demonstrated that nurses staffing home ventilator cases were unable to complete basic airway assessments, identify ventilator alarms and their significance, and had difficulties with tracheostomy tube changes. ${ }^{14}$

The absence of well-prepared caregivers places these children at high risk for adverse outcomes including hospital readmission, morbidity, and death. ${ }^{3,7,15}$ Caring for a child on a ventilator at home offers a number of challenges. The HCS may often be alone with the child and, unlike the hospital setting, may not be able to obtain immediate assistance in the event of an emergency. Duties that are often managed by respiratory therapy in the hospital setting are now provided by a home care nurse with limited experience addressing ventilator alarms, administering respiratory medications, and managing an artificial airway. In addition, when home care staff lack confidence in their skills and have knowledge deficits, this interferes with the development of a collaborative relationship between the family and home care staff. ${ }^{16}$

An evaluation of existing models of education for $\mathrm{HCS}^{15,17-19}$ revealed various content, length, and complexity. Courses ranged from $2 \mathrm{~h}$ covering only tracheostomy care $\mathrm{c}^{9,20}$ to a $32 \mathrm{~h}$ comprehensive program ${ }^{17}$ covering anatomy, physiology, and both tracheotomy and ventilator care. Our goal was to develop a hybrid program with both tracheostomy and ventilator content focused primarily on those events and situations most likely to result in morbidity and mortality including tracheostomy decannulation, mucus plugging, and ventilator malfunction. The two primary barriers to training consistently identified by home health agencies were limited financial resources and limited staffing resulting in little time to attend training courses. In order to address these barriers, we designed the program in a 4-h block which could be completed in a half day allowing staff to work a shift and still attend the program. The content base assumed that participants would have some background in anatomy and physiology and some degree of experience with care of children with tracheostomy and ventilator dependence and thus focused on identification of and intervention for the highest risk situations.

The goal of this project was to evaluate the efficacy of a short, focused, mixed modality, simulation based training program provided in the local community for HCS focused on teaching emergency tracheostomy and ventilator maneuvers. The course was developed and delivered by expert nursing and respiratory care staff from the University of Michigan Pediatric Home Ventilator Program. We hypothesized that, after attending the course, the home care staff would demonstrate an improvement in emergency response skills as measured by improvement in test scores and self-reported improvement in comfort level with care. An application was made to the Institutional Review Board which determined this work was not regulated (HUM00104617) as it was deemed a quality improvement project.

\section{2 | METHODS}

A phone survey of seven national and local private duty nursing agencies providing private duty nursing services to children in the state of Michigan was conducted to evaluate the emergency education provided to home care nurses (Table 1). The survey revealed varying degrees of education and competency validation provided upon hire, however, there were no requirements documented for ongoing education to maintain competency. Supervisors note barriers to staff education to include lack of agency funding to support travel and attendance at conferences.

Based on this needs assessment and a review of the literature, ${ }^{15,17-19}$ a comprehensive, simulation based, training course was developed to include content on emergency tracheostomy maneuvers and ventilator information (Table 2). We chose to include both Trilogy and LTV ventilators in this program as these were the most commonly used ventilators in our region. Simulation was chosen because it is an effective method for adults to become confident and competent in a new skill, especially in cases where learners have some previous experience in the skill set. ${ }^{21}$ Our program built upon the participants' previous knowledge of tracheostomy and ventilator management. ${ }^{19,21}$ Self-evaluation was utilized in this educational model because it is 
TABLE 1 Need assessment of local and state private duty agencies

\begin{tabular}{|c|c|c|c|c|}
\hline Agency & Orientation upon hire & $\begin{array}{l}\text { Orientation at opening of } \\
\text { each case }\end{array}$ & Ongoing competency & Comments \\
\hline 1 & $\begin{array}{l}\text { 2-day orientation including } 2 \mathrm{~h} \text { vent } \\
\text { training with agency RRT, Trach } \\
\text { video, doll demo, written test } \\
\text { must be passed }\end{array}$ & $\begin{array}{l}2 \mathrm{~h} \text { opening supervisor and all } \\
\text { assigned nurses. Supervisor } \\
\text { and family does training, } \\
\text { DME RRT does vent } \\
\text { training }\end{array}$ & $\begin{array}{l}2 \text { in-services per year } \\
\text { varying topics, not } \\
\text { necessarily trach/vent }\end{array}$ & $\begin{array}{l}\text { Any new nurse coming on case } \\
\text { gets assigned to spend } 4- \\
16 \mathrm{~h} \text { with experienced nurse. } \\
\text { Have a competency checklist }\end{array}$ \\
\hline 3 & $\begin{array}{l}8 \mathrm{~h} \text { all day, online trach video, hands } \\
\text { on vent with UM RRT }\end{array}$ & $\begin{array}{l}\text { Supervisors go to home with } \\
\text { each new case and orient } \\
\text { staff. Have checklist very } \\
\text { "generic" }\end{array}$ & $\begin{array}{l}\text { Varies from year to year. } \\
\text { Nurses must complete } \\
\text { JACHO required } \\
\text { activates. }\end{array}$ & $\begin{array}{l}\text { New nurse works with existing } \\
\text { nurse for orientation } 8-16 \mathrm{~h}\end{array}$ \\
\hline 5 & $\begin{array}{l}2 \mathrm{~h} \text { vent training with LTV } 800 \text { and } \\
\text { agency RT/RN Trach training with } \\
\text { demo dolls }\end{array}$ & $\begin{array}{l}\text { Competency checklist for all } \\
\text { cases. Supervisors open } \\
\text { case and evaluate } \\
\text { competency }\end{array}$ & $\begin{array}{l}\text { No ongoing trach/vent } \\
\text { competency }\end{array}$ & $\begin{array}{l}\text { Has a competency checklist } \\
\text { completed upon case } \\
\text { opening and for each newly } \\
\text { assigned nurse }\end{array}$ \\
\hline 6 & $\begin{array}{l}\text { In office competency, done by nurse } \\
\text { manager trach care, CPR, vent } \\
\text { training } 16 \text { hours. No written test, } \\
\text { competency checklist filled out }\end{array}$ & $\begin{array}{l}\text { Orientation-spend } 24 \mathrm{~h} \text { with } \\
\text { another nurse familiar with } \\
\text { case. Vent training occurs at } \\
\text { a home by nurse manager }\end{array}$ & $\begin{array}{l}\text { Annual-competency } \\
\text { emergency trach } \\
\text { maneuvers, they have } \\
\text { anatomical infants, no } \\
\text { ventilator training }\end{array}$ & $\begin{array}{l}\text { Some families request to orient } \\
\text { new nurse. RN assessments } \\
\text { QA }\end{array}$ \\
\hline
\end{tabular}

paramount to creating a deep understanding and incorporation of the educational material. ${ }^{19,21-23}$

We sought to evaluate the effects of our teaching. We found no validated evaluation tools to measure efficacy of tracheostomy and/or ventilator instruction. The work by Dorton, ${ }^{20}$ focused exclusively on tracheostomy education of hospital based providers, utilized a 10 question self-assessment which included items evaluating comfort with tracheostomy management along with a 15 item objective test.

TABLE 2 Program content

\begin{tabular}{|c|c|c|}
\hline Time & Method & Topic \\
\hline $30 \mathrm{~min}$ & $\begin{array}{l}\text { Lecture/ } \\
\text { slides }\end{array}$ & $\begin{array}{l}\text { Emergency airway/tracheotomy } \\
\text { skills }\end{array}$ \\
\hline $45 \min$ & $\begin{array}{l}\text { Hands on } \\
\text { stations }\end{array}$ & $\begin{array}{l}\text { Obstructed airway, accidental } \\
\text { decannulation, } \\
\text { "Go Bag" }\end{array}$ \\
\hline $45 \min$ & $\begin{array}{l}\text { Lecture/ } \\
\text { slides }\end{array}$ & Trilogy and LTV ventilators \\
\hline $60 \mathrm{~min}$ & $\begin{array}{l}\text { Hands on } \\
\text { stations }\end{array}$ & $\begin{array}{l}\text { Skills-tracheotomy and ventilator } \\
\text { simulations } \\
\text { Check list completion } \\
\text { demonstrations }\end{array}$ \\
\hline
\end{tabular}

These tools were completed before education, immediately and 6 months after the program. In evaluating the competency of home care staff and family caregivers, $\mathrm{Kun}^{6}$ developed a 10 item multiple choice tool focused exclusively on ventilator management including alarm identification and trouble shooting. While neither of these tools was validated, our group did reference them in development of our evaluation tools.

Two tools were used to objectively measure change, using a pre and posttest model. The first was a five item Likert style selfassessment quantifying individual comfort level with performing tracheostomy and ventilator maneuvers (Table 3 ). The second part of the assessment was an 11 item multiple choice test reflecting knowledge level (Table 4).

Local events were scheduled in three geographically neutral areas in which participants had a $1 \mathrm{~h}$ or less estimated travel time. Each session was designed in a half day format to allow for participants to work if desired. This local design was an outcome of the needs assessment which revealed that community based staff required educational offerings which were short in order to minimize time away from work and provided within the community to reduce expenses of driving and potential overnight stays. A fee of $\$ 50$ was charged to secure registration. Continuing education contact hours were granted. 
TABLE 3 Scores of self-assessment of comfort with care

\begin{tabular}{|c|c|c|c|}
\hline Statement & Pre test score/SD & Post test & Change \\
\hline $\begin{array}{l}\text { I feel comfortable taking care of a child with a tracheotomy \& ventilator } \\
\text { when the family is not at home }\end{array}$ & $3.3(1.4)$ & $4.2(1.0)$ & $+0.9(1.4)$ \\
\hline I am able to quickly assess a ventilator alarm on a Trilogy and intervene & $2.9(1.3)$ & $4.1(0.9)$ & $+1.1(1.3)$ \\
\hline I feel comfortable changing the tracheotomy tube for a routine change & $3.7(1.2)$ & $4.3(0.8)$ & $+0.6(1.1)$ \\
\hline
\end{tabular}

Score range: 1 , very uncomfortable; 2 , uncomfortable; 3 , neither comfortable or uncomfortable; 4 , comfortable; 5 , very comfortable.

Hands on sessions were provided using clinical simulation models. Two simulation scenarios were included in the session, one with tracheostomy tube mucus plugging and the second with tracheostomy tube decannulation. An internet based search revealed no commercially available simulation model with both a tracheostomy tube and inflatable lungs. Therefore, a Laerdal Baby Annie CPR infant mannequin (Laerdal Medical, Wappingers Falls, NY) with inflatable lungs was modified by cutting into the plastic airway and inserting an uncuffed Bivona 3.0 neonatal tracheostomy tube. This was a tight enough fit to allow for seal of the airway and chest rise with the delivery of breaths provided by both the ventilator and resuscitation bag. Mechanically occluded tracheostomy tubes were placed to simulate mucus plugging.

TABLE 4 Test scores

\begin{tabular}{|c|c|c|c|c|}
\hline & Question content area & Pretest $^{\mathrm{a}}$ & $\begin{array}{l}\text { Post } \\
\text { test }^{\text {a }}\end{array}$ & Change \\
\hline 1 & $\begin{array}{l}\text { Mucus plug assessment } \\
\text { LTV alarm high } \\
\text { pressure }\end{array}$ & 49 & 54 & +5 \\
\hline 2 & $\begin{array}{l}\text { Decannulation } \\
\text { assessment LTV alarm } \\
\text { low pressure }\end{array}$ & 19 & 41 & +22 \\
\hline 3 & $\begin{array}{l}\text { Using one size smaller } \\
\text { trach tube }\end{array}$ & 46 & 50 & +4 \\
\hline 4 & Symptoms of mucus plug & 43 & 49 & +6 \\
\hline 5 & Choosing one size smaller & 29 & 54 & +25 \\
\hline 6 & Prevent mucus plug & 39 & 46 & +7 \\
\hline 7 & $\begin{array}{l}\text { Checking tracheostomy } \\
\text { cuff }\end{array}$ & 29 & 43 & +14 \\
\hline 8 & Pulse ox use & 39 & 47 & +8 \\
\hline 9 & Pulse ox alarms & 27 & 39 & +12 \\
\hline 10 & Trilogy alarm & 29 & 39 & +10 \\
\hline 11 & $\begin{array}{l}\text { Nonfunctional vent in } \\
\text { patient with } \\
\text { quadriplegia }\end{array}$ & 20 & 28 & +8 \\
\hline & Average score & $62 \%$ & $82 \%$ & $\begin{array}{l}20 \% \\
\qquad(P>0.0001)\end{array}$ \\
\hline
\end{tabular}

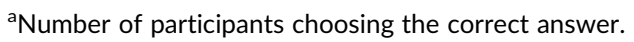

Apple IPads with DART ECG simulation application (D.A.R.T. SIM 2555 Carnino Del Rio South Suite\#201 San Diego, CA) were utilized to simulate pulse oximeter and heart rate readings associated with an acute event such as mucus plugging or accidental decannulation. These simulation screens were loaded on both the IPad and the instructor cell phone which could then provide live, in time feedback to learners on the efficacy of their interventions. At each station was an emergency "Go Bag" which contained all the equipment for an emergency airway event. Participants were cued by instructors to identify both the same size and the one size smaller tracheostomy tubes for the sample patient.

Finally, participants received extensive decision making support when dealing with airway emergencies. Both in the lecture portion of the program and again in the skills simulation stations learners where prompted to progress through a decision making algorithm to appropriately triage and intervene in airway emergencies and ventilator alarms. After completing all components of the training, participants completed the post selfevaluation tool which included comfort with skills and competency assessment.

\section{1 | Statistical analysis}

Basic univariate analyses were used to describe sample demographics and baseline test scores. Paired $t$ tests were used to determine if there were statistically significant differences between pre and posttest comfort and test scores. We used Spearman rank-order correlation to assess whether comfort scores or participant demographic characteristics were associated with skill test scores.

\section{3 | RESULTS}

\section{1 | Demographics}

Of the 54 participants the majority $n=40$ (74\%) were female. Most were RNs (68\%) followed by LPN (19\%) and respiratory therapists (12\%). Sixty-nine percent of participants had an associate's degree, $19 \%$ had bachelor's degrees, and $13 \%$ has post master degrees. This was a predominately older group with the largest percentage falling in 
the 50 -59-year-old range (44\%), with $28 \%$ being between 30 and 39 years. Total clinical experience is consistent with the older age range, with $30 \%$ having over 20 years of total clinical experience. It is interesting to note that despite significant years of clinical experience, participants were fairly new to pediatric care with $52 \%$ having 4 years or less of pediatric experience and were also relatively new to home care with $63 \%$ with 4 years of less of home care experience (Table 5).

TABLE 5 Participant demographics

\begin{tabular}{|c|c|}
\hline Variable & Number/percent \\
\hline \multicolumn{2}{|l|}{ Age } \\
\hline $20-29$ & $1(2)$ \\
\hline $30-39$ & $15(28)$ \\
\hline $40-49$ & $10(19)$ \\
\hline $50-59$ & $24(44)$ \\
\hline Over 60 & $4(7)$ \\
\hline \multicolumn{2}{|l|}{ Gender } \\
\hline Male & $14(26)$ \\
\hline Female & $40(74)$ \\
\hline \multicolumn{2}{|l|}{ Licensure } \\
\hline $\mathrm{RN}$ & $37(69)$ \\
\hline LPN & $10(19)$ \\
\hline RRT & $6(11)$ \\
\hline CRT & $1(1)$ \\
\hline \multicolumn{2}{|l|}{ Education } \\
\hline Associate degree & $37(69)$ \\
\hline Bachelor degree & $10(19)$ \\
\hline Master's degree & $5(9)$ \\
\hline Post master degree & $2(4)$ \\
\hline \multicolumn{2}{|c|}{ Total years clinical experience } \\
\hline $0-4$ & $14(26)$ \\
\hline $5-9$ & 9 (17) \\
\hline $10-14$ & $7(13)$ \\
\hline $15-19$ & $5(9)$ \\
\hline Over 20 & $19(35)$ \\
\hline \multicolumn{2}{|c|}{ Total years pediatric experience } \\
\hline $0-4$ & $28(52)$ \\
\hline $5-9$ & $18(33)$ \\
\hline $10-14$ & $4(7)$ \\
\hline $15-19$ & $1(1)$ \\
\hline Over 20 & $3(5)$ \\
\hline \multicolumn{2}{|c|}{ Total years home care experience } \\
\hline $0-4$ & $34(63)$ \\
\hline $5-9$ & $15(27)$ \\
\hline $10-14$ & $3(5)$ \\
\hline $15-19$ & $2(4)$ \\
\hline Over 20 & $0(0)$ \\
\hline
\end{tabular}

\section{2 | Self-reported comfort level}

Participants had an average pre-course comfort level of 3.3 (on a scale of 1-5, one being very uncomfortable and 5 being very comfortable). The areas of greatest discomfort were assessment and triage of ventilator alarms. Of particular concern is the score of 3.3 reflecting comfort level providing care when the family is not at home indicating that most participants had some concerns about being alone with the ventilator dependent child. The post intervention comfort level rose to 4.2 with the greatest gains in the comfort with ventilator alarms. Selfreported comfort with emergency skills demonstrated a significant increase after intervention $(P>0.0001)$ (Table 3).

\section{3 | Skills assessment test scores}

The average pre-test score was 6.8 correct of 11 items (62\%). The participants scored low on questions requiring them to check the patient before the equipment, alarms associated with tracheostomy decannulation and choosing the correct size smaller tracheostomy tube. The average post test score was 9.0 out of 11 items (82\%) reflecting an improvement of 20 percentage points overall. The greatest improvements in scores were on questions regarding ventilator alarms and correct tracheostomy tube sizes. The participants continued to have difficulty with the concept of checking the patient before the equipment. Test scores improved significantly after intervention $(P>0.0001)$ (Table 4$)$.

\section{4 | Factors predicting higher scores}

We were interested in individual factors which may predict higher scores on self-assessment of comfort and on skills test. Therefore, the variables of participant age and participant years of experience were correlated with pre-intervention comfort and test scores. The only variable that correlated with higher self-assessment of comfort was years of home care experience $(P<0.0001)$, however, this same effect was not seen in skills assessment pretest correlations, suggesting that participants may over estimate their own skill level. This finding is particularly concerning as individuals who perceive themselves to be able to perform certain tasks may have a lower likelihood of attending continuing education courses (Table 6).

TABLE 6 Variables associated with higher pre intervention test and comfort scores

\begin{tabular}{|lll|}
\hline Variable & Rho & $P$-value \\
\hline $\begin{array}{c}\text { Pre intervention comfort score and } \\
\text { Total number of years of experience }\end{array}$ & 0.1 & 0.48 \\
\hline$\quad$ Years of pediatric experience & 0.41 & 0.002 \\
\hline$\quad$ Years of home care experience & 0.52 & $<0.0001$ \\
\hline $\begin{array}{l}\text { Pre intervention test score and } \\
\quad \text { Total number of years of experience }\end{array}$ & 0.05 & 0.74 \\
\hline$\quad$ Years of pediatric experience & 0.16 & 0.23 \\
\hline$\quad$ Years of home care experience & 0.16 & 0.24 \\
\hline
\end{tabular}




\section{4 | DISCUSSION}

We hypothesized that a condensed structured, simulation based education program on emergency tracheostomy and ventilator maneuvers provided in the local community could improve the emergency response skills and comfort of community based HCS. This hypothesis was supported by the significant improvement in comfort and skills test scores. Our participant pre-test scores were comparable to others ${ }^{7,10,11,13}$ demonstrating that health care providers have opportunities to improve their emergency response skills. Participants demonstrated lower scores on the self-assessment of comfort scores which suggests that HCS are aware of the need for ongoing skill development, and seek to improve their confidence and knowledge. It is interesting to note that while HCS seek educational opportunities, no structured skills programs were available either at an agency level or state level to provide education to HCS to gain the skills necessary to improve their ability to provide safe care for patients at home with tracheostomies and ventilators.

Our program design utilized a unique combination of didactic and simulation including both tracheostomy and ventilator content in a short amount of time, focused exclusively on the most at risk situations including tracheostomy decannulation/plugging and ventilator malfunction. Our results suggest this was effective and are consistent with others ${ }^{22}$ who note that patient simulation was an effective teaching method and provided a mechanism to create participant confidence and competence thereby promoting safety with care at home. Our program is the first to describe this short, risk focused, simulation program focusing on tracheostomy, and ventilator care specifically designed for HCS. Others have described the use of didactic and simulation methods to teach primary care physicians, residents, and advanced practice nurses tracheostomy care and management skills, ${ }^{10,11,20,23}$ however, none of these have included ventilator management. While tracheostomy skills are important, mastery of tracheostomy management skills alone would not achieve the goal of improved patient safety. The inclusion of ventilator management skills provides the comprehensive skill set necessary to deliver safe care in the home environment.

Participants demonstrated statistically significant improvement in the post intervention skills test score. The magnitude of change in pre- to post-test scores is similar to those reported after a comprehensive 4-day, 32-h instructional program ${ }^{17}$ and a short two hour tracheostomy focused program. ${ }^{20}$ Others have described tracheostomy and ventilator simulation with infants utilizing a shorter 2 -h program, however, did not include objective measures of outcomes. ${ }^{14}$ The fact that critical emergency skills can be taught in a short, time manageable and cost effective, community based course is important. Agencies and stake holders, including regional ventilator teams, can develop similar programs utilizing the main objectives outlined in this program and modify the content to meet their specific needs. The program then can be easily and cost effectively implemented at the agency or regional level with minimal impact on patient service and cost, yet has the potential to provide significant improvement in safety and patient outcomes.

We found many barriers to staff education including cost and ability to take time away from work. These are consistent with barriers described by others ${ }^{19,22}$ which also include lack of time, confidence, information, and motivation and scheduling problems. Some agencies were noted to be reluctant to promote this event secondary to the cost. Supervisory staff explained that Medicaid reimbursement rates for home care services were so low they could not afford to give staff paid time to attend this program and were not able to cover the cost. Others relayed they felt this session was a "repeat" of branch office orientation. The low pre intervention comfort scores and test scores reflect that in house orientation received by participants was not sufficient to establish competency. This program was designed to address these barriers by providing education in a short and cost effective manner.

Finally, national standards for continuing education and competency should be developed for all professionals who provide home care to ventilator dependent children. These standards would then provide the rationale necessary to require agencies to provide and cover the cost of continuing education. The American Academy of Pediatrics report on financing home health care recommends home health care payments be increased to permit agencies to both attract well qualified home care staff and to retain this staff. In addition, reimbursement rates must support ongoing education of home nursing staff in areas of safety and technology. ${ }^{24}$ An added benefit to higher overall reimbursement rates and the availability of highly competent home care staff is the potential reduction in inpatient hospital days. ${ }^{25}$

There are many variables which affect the results of this study. In any pre/posttest design there is the possibility of participants "learning" the test and cuing into information which results in significant improvements in post test score. The sample was small and was not random, therefore, the results may not be generalizable to broad populations of home care staff. The authors developed measurement tools based on previously published quality improvement data ${ }^{6,10}$ and reflected content and skills most often cited in adverse events. These tools were not tested for validity and reliability.

\section{1 | Future research}

Opportunities for further research include quantification of improvements in nursing care after nurses have attended the classes. This would include collection of post intervention adverse event data as well as assessment of family comfort and satisfaction with nursing care. Additionally, our study does not evaluate for knowledge retention beyond the 4-h session. It is likely that periodic refresher courses will be necessary to maintain proficiency. Additional research could aim to determine the best interval for updates and also evaluate alternative methods of delivery including center based or web based models and variables that affect retention.

\section{5 | CONCLUSION}

Children requiring tracheostomy and mechanical ventilator support are at high risk for adverse outcomes related to their technology. These children require highly trained caregivers to maintain a safe and healing environment for them to grow and thrive. HCS is a critical part of the 
community-based team who provide one-on-one care to allow families to rest and attend to other family commitments. In order to fulfill this role and to maintain a safe environment for the child, HCS must have a high degree of competency and confidence in their skill should an airway or ventilator emergency occur. Our study demonstrated that HCS need opportunities to improve their emergency response skills. A 4-h, risk focused, simulation based intervention focusing on tracheostomy emergencies and ventilator management was effective in increasing the skill and comfort level of the participants. This short course can be easily implemented in individual nursing agencies. The 4-h timeframe allows for participants to engage in a full work day and, depending on the resources of the agency, this course could be offered free of charge. Further research is needed to determine whether or not this type of course leads to improved patient outcomes. Additionally, it would be important to assess whether or not participants have longterm retention of the information provided in the training session, to help determine a recommendation for frequency of retraining to maintain competency. On a more macro level, providers throughout the continuum of care from medical staff in the acute care facilities to community-based staff and parents and families as well as policy makers need to come together to validate the critical role of HCS and to provide appropriate financial support concurrent with the degree of skill and risk associated with these services. With appropriate financial resources agencies can offer ongoing education to promote a high competency level among all homecare staff.

\section{ORCID}

Ann Marie Ramsey (iD http://orcid.org/0000-0002-6761-8185

\section{REFERENCES}

1. Watters K, Neill M, Zhu H, Graham RJ, Hall M, Berry J. 2-year mortality, complications, and healthcare use in children with Medicaid following tracheostomy. Laryngoscope. 2016;126:2611-2617.

2. Kun SS, Davidson-Ward SL, Hulse LM, Keens TG. How much do primary care givers know about tracheostomy and home ventilator emergency care? Pediatr Pulmonol. 2010;45:270-274.

3. Rieter K, Pernath N, Pgel P, et al. Risk factors for morbidity and mortality in pediatric home mechanical ventilation. Clin Pediatr. 2011;50:237-243.

4. Edwards JD, Kun SS, Keens TG. Outcomes and cause of death in children on home mechanical ventilation via tracheostomy: and institutional and literature review. J Pediatr. 2010;157:955-959.

5. Zhu H, Das P, Roberson DW, et al. Hospitalizations in children with pre-existing tracheostomy: a national perspective. Laryngoscope. 2014;125:462-468

6. Kun SS, Beas VN, Keens TS, Ward SL, Gold Jl. Examining pediatric emergency home ventilation practices in home health nurses: opportunities for improved care. Pediatr Pulmonol. 2013;45:1-7.

7. Kleinman ME, Chameides L, Schexnayder SM, et al. Pediatric advanced life support: 2010 American Heart Association guidelines for cardiopulmonary resuscitation and emergency cardiovascular care. Pediatrics. 2010;126:e1361-e1399.
8. Boroughs D, Dougherty J. Decreasing accidental mortality of ventilator dependent children at home. Home Health Care Nurse. 2012;30:103-111.

9. Agarwal A, Marks N, Wessel V, et al. Improving knowledge, technical skills, and confidence among pediatric healthcare providers in the management of chronic tracheotomy using a simulation model. Pediatr Pulmonol. 2016;51:696-704.

10. Sterni L, ATS Pediatric Chronic Home Ventilation Workgroup. An official American Thoracic Society clinical practice guideline: pediatric chronic home invasive ventilation. Am J Respir Crit Care Med. 2016;193:e16-e35.

11. Khademi A, Cuccurulo SJ, Cerillow LM, et al. Tracheostomy management skills and competency in physical medicine and rehabilitation residents: a method for development and assessment. Am J Phys Med Rehab. 2012;91:65-74.

12. Casserly P, Lang E, Fenton J, Walsh M. Assessment of healthcare professionals' knowledge of managing emergency complications in patients with tracheostomy. Br J Anaesth. 2007;99:380-383.

13. Smith-Miller S. Graduate nurses comfort and knowledge level regarding tracheotomy care. J Nurs Staff Dev. 2006;22:222-229.

14. Carter J, Prater D, Haycraft A, et al. Tracheotomy/home ventilator emergencies: simulation training for home care nurses. Abstract Am J Respir Crit Care Med. 2014;189:A5249.

15. Docherty J, Parrish J, Parra M, Kinney Z, Kandrack A. Using a competency base curriculum to train experienced nurses and ventilator care. Pediatr Nurs. 1996;22:47-50.

16. Romer $\mathrm{N}$. The tracheotomized child: private duty nursing at home. Home Health Care Nurse. 1997;10:28-32.

17. Boroughs D, Dougherty J. Care of technology-dependent children in the home. Home Health Care Nurse. 2009;27:37-42.

18. Hewitt-Taylor J. Caring for children with complex ne eds staff education and training. J Child Heath Care. 2005;9:72-86.

19. Trivette C, Dunst C, Hamby D, O'Herin C. Characteristics and consequences of adult learning methods and strategies. Res Brief. 2009;3:1. Tots n Tech Research Institute.

20. Dorton L, Lentzenich C, Evans A. Simulation model for tracheotomy education for primary health care providers. Ann Otol Rhinol Laryngol. 2014;123:11-18.

21. Clapper T. Beyond Knowledge: what those conducting simulation need to know about adult learning theory. Clin Simul Nurs. 2010;6: e7-e14.

22. Unsworth J, Tuffnell C, Platt A. Safer care at home: use of simulation training to improve standards. Br J Commun Nurs. 2011;16:334-339.

23. Sudikoff S, Overly F, Shapiro M. High Fidelity medical simulation as a technique to improve pediatric resident's emergency airway management and team work: s pilot study. Pediatr Emerg Care. 2009;25:651-656.

24. Mclnerny TK, Barone $C J$, Johnson AD, et al. Committee on child health financing 2004-2005. Financing of pediatric home health care. Pediatrics. 2006;118:834-838.

25. Sobotka S, Hird-McCorry L, Goodman D. Identification of fail points for discharging pediatric patients with new tracheostomy and ventilator. Hosp Pediatr. 2016;6:552-554.

How to cite this article: Ramsey AM, Brennan S, Stricker A, et al. Emergency airway and ventilator procedures for community based home care staff validation of an educational program. Pediatric Pulmonology. 2018;53:374-380. https://doi.org/10.1002/ppul.23936 